University of Nebraska - Lincoln

DigitalCommons@University of Nebraska - Lincoln

June 2006

\title{
The 15-kDa selenoprotein (Sep15): functional analysis and role in cancer
}

Vyacheslav M. Labunskyy

University of Nebraska-Lincoln

Vadim N. Gladyshev

University of Nebraska-Lincoln, vgladyshev@rics.bwh.harvard.edu

Dolph L. Hatfield

National Cancer Institute, National Institutes of Health, Bethesda, MD

Follow this and additional works at: https://digitalcommons.unl.edu/biochemgladyshev

Part of the Biochemistry, Biophysics, and Structural Biology Commons

Labunskyy, Vyacheslav M.; Gladyshev, Vadim N.; and Hatfield, Dolph L., "The 15-kDa selenoprotein (Sep15): functional analysis and role in cancer" (2006). Vadim Gladyshev Publications. 41.

https://digitalcommons.unl.edu/biochemgladyshev/41

This Article is brought to you for free and open access by the Biochemistry, Department of at DigitalCommons@University of Nebraska - Lincoln. It has been accepted for inclusion in Vadim Gladyshev Publications by an authorized administrator of DigitalCommons@University of Nebraska - Lincoln. 


\title{
SELENIUM \\ Its Molecular Biology and Role in Human Health, Second Edition
}

Edited by

\author{
Dolph L. Hatfield \\ National Cancer Institute, USA \\ Marla J. Berry \\ University of Hawaii, USA \\ and \\ Vadim N. Gladyshev \\ University of Nebraska, USA
}

黛 Springer

2006 


\title{
Chapter 13. The 15-kDa selenoprotein (Sep15): functional analysis and role in cancer
}

\author{
Vyacheslav M. Labunskyy and Vadim N. Gladyshev
}

Department of Biochemistry, University of Nebraska, Lincoln, NE 68588, USA

Dolph L. Hatfield

Section on the Molecular Biology of Selenium, Laboratory of Cancer Prevention, National Cancer Institute, National Institutes of Health, Bethesda, MD 20892, USA

Summary: The $15-\mathrm{kDa}$ selenoprotein (Sep15) was identified several years ago as a protein of unknown function. In recent years, several lines of evidence implicated Sep15 in the effect of dietary selenium in cancer prevention. These lines of evidence include: 1) protein expression patterns in normal and malignant cells; 2) identification of polymorphic sites that regulate Sep 15 levels and differentially respond to selenium supplementation; 3) location of the Sep15 gene in the human genome; and 4) correlation between Sep 15 haplotype and susceptibility to cancer. Functional analyses revealed a specific interaction between Sep 15 and a protein folding sensor in the endoplasmic reticulum of mammalian cells and identified Sep15 as a novel thioredoxin-like fold redox regulator. Sep15 defines a new protein family that occurs in several organisms from green algae to mammals and also contains selenoprotein $\mathrm{M}$ (SelM) and a recently identified fishspecific selenoprotein Fep15.

\section{Introduction}

Selenium, an important micronutrient, has been implicated in reducing the incidence of cancer in different animal models and human clinical trials [13]. As discussed in many chapters in this book, this trace element is incorporated into proteins in the form of selenocysteine and is often present at the active centers of selenium-containing enzymes. This chapter describes one such protein, designated the 15-kDa selenoprotein (Sep15). Sep15 was identified in 1998 by purifying and characterizing a protein from human $T$ cells [4]. This protein was subsequently implicated in the cancer prevention effect of dietary selenium [5], and more recently in regulation of redox homeostasis in the endoplasmic reticulum (ER) [6]. This chapter provides up to date information on Sep15 and members of its family. 


\section{Potential role of Sep15 in cancer prevention}

Several selenoproteins have been proposed as candidates that are responsible for the cancer prevention potential of selenium. Among these proteins is Sep15 that has been implicated in mediating the chemopreventive effect of selenium in certain types of cancers, including liver [5], prostate [7], breast [8], and lung malignancies [9].
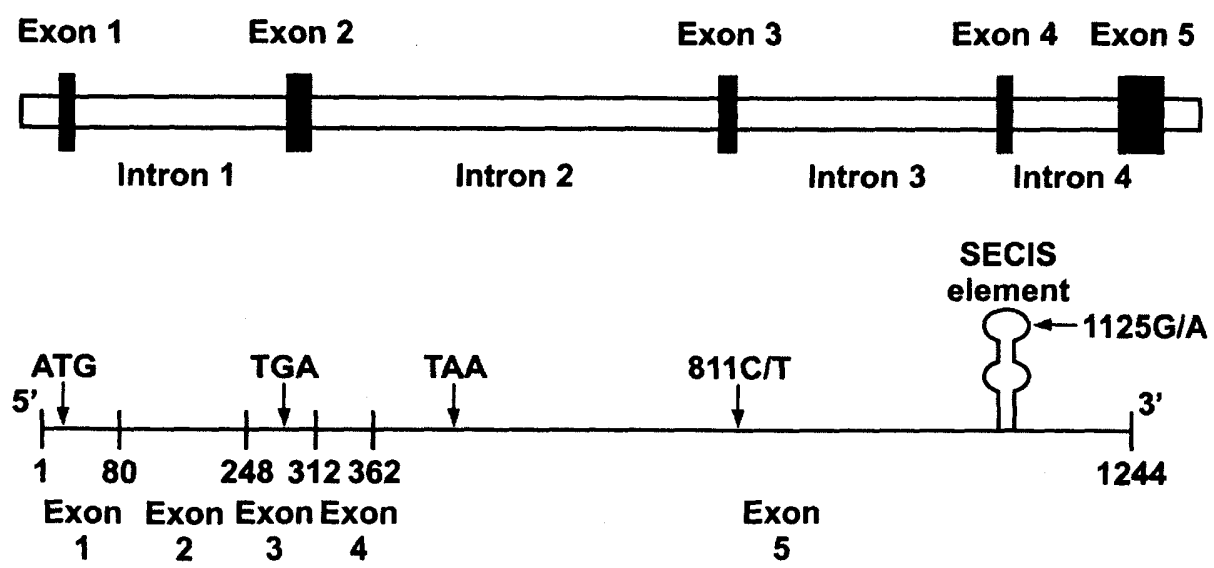

Figure 1. Structural organization of the human Sep15 gene. The upper panel shows exonintron organization of the Sep15 gene. Closed squares correspond to exons, and horizontal lines correspond to introns and flanking regions. The lower panel shows organization of the human Sep15 cDNA sequence. The relative positions of the ATG initiation and the TGA Sec codons, the TAA termination signal and the single nucleotide polymorphisms $(811 \mathrm{C} / \mathrm{T}$ and $1125 \mathrm{G} / \mathrm{A}$ ) are indicated. The long horizontal line corresponds to the Sep15 cDNA, and short vertical lines correspond to exon-exon junctions. Numbers under junction sites correspond to last nucleotides in preceding exons.

The following lines of evidence make an argument for a possible role of Sep15 in cancer etiology. The human gene encoding Sep15 is located on chromosome 1 at position p31, a locus commonly deleted or mutated in human cancers and implicated in tumor suppression [10,11]. Sep15 expression was found to be significantly decreased in more than half of the tested cancer samples and tumor cell lines as compared to corresponding controls [5,9]. Genetic analysis of the human Sep15 gene revealed the presence of two polymorphisms that show strong allelic association [5]. These two single nucleotide polymorphisms (SNPs) are located at positions $811(\mathrm{C} / \mathrm{T})$ and $1125(\mathrm{G} / \mathrm{A})$ in the Sep15 mRNA (see Figure 1). The latter polymorphism is, in fact, part of the SECIS element, an RNA structure in the 3 '-untranslated region required for recognition of in-frame UGA codons as selenocysteine. This SNP appears to influence expression of Sep15 in a 
selenium-dependent manner. The A1125 variant resulted in a higher expression of the selenoprotein, but it could not efficiently respond to the addition of selenium in the cell culture medium $[5,7,12]$. Thus, this SNP directly influenced the expression levels of Sep15, and the outcome was dependent on the selenium status. These data suggested that individuals differing in these alleles may not only differ in Sep 15 levels but also in the response to selenium dietary supplements. The polymorphisms have further relevance to cancer. The A1125 form is prevalent in African Americans who are known to have a higher incidence of prostate cancer [7]. It also should be noted that the highest expression of Sep15 is observed in the prostate [5]. It is conceivable that African Americans require higher levels of selenium to achieve the protective levels of Sep15 expression. In addition, it was found that African Americans showed differences in allelic frequency in head, neck, and breast cancers and examples of the loss of heterozygosity at the Sep15 locus also were observed [7].

Recent studies from other groups provide further evidence in support of these observations. For example, the A1125 form was found to be less responsive than the G1125 form to the selenium that showed growth inhibitory and apoptotic effects [9].

\section{Interaction of Sep15 with UDP-glucose:glycoprotein glucosyltransferase}

During initial purification from a human T-cell line, Sep15 was isolated in the denatured state [4]; however, native Sep15 isolated from rat prostate and mouse liver co-purified with a protein of $\sim 160-240 \mathrm{kDa}$. The binding partner of Sep15 was identified as UDP-glucose:glycoprotein glucosyltransferase (UGT), an ER chaperone and essential regulator of the calnexin cycle [6]. The calnexin cycle is a quality control pathway localized to the ER that specifically assists in the folding of N-linked glycoproteins [13]. In this quality control pathway, UGT functions as the folding sensor that recognizes unfolded or improperly folded glycoproteins (Figure 2). UGT catalyzes the transfer of a glucose moiety from UDP-glucose to the glycan core [14] that creates a retention signal and initiates binding of membrane-bound calnexin and its lumenal homologue calreticulin to the glycan [15-18]. This triggers the binding of ERp57 (a lumenal protein disulfide isomerase) to calnexin and calreticulin, and accelerates folding by catalyzing disulfide bond exchange [19-23]. The tight association of Sep15 and UGT in 1:1 ratio (with apparent $K_{d}$ of $20 \mathrm{nM}$ ) suggests that this selenoprotein may modulate the enzymatic activity of UGT and/or be involved in assessing structural fidelity [24]. This role is also supported by the observation that expression of Sep15 is activated by the unfolded protein response (UPR), a signaling pathway activated in response to accumulation of unfolded proteins in the ER [25]. The UPR pathway results in enhanced expression of genes encoding proteins 
that facilitate protein folding and help cells remove incorrectly folded and/or excess proteins in the ER.

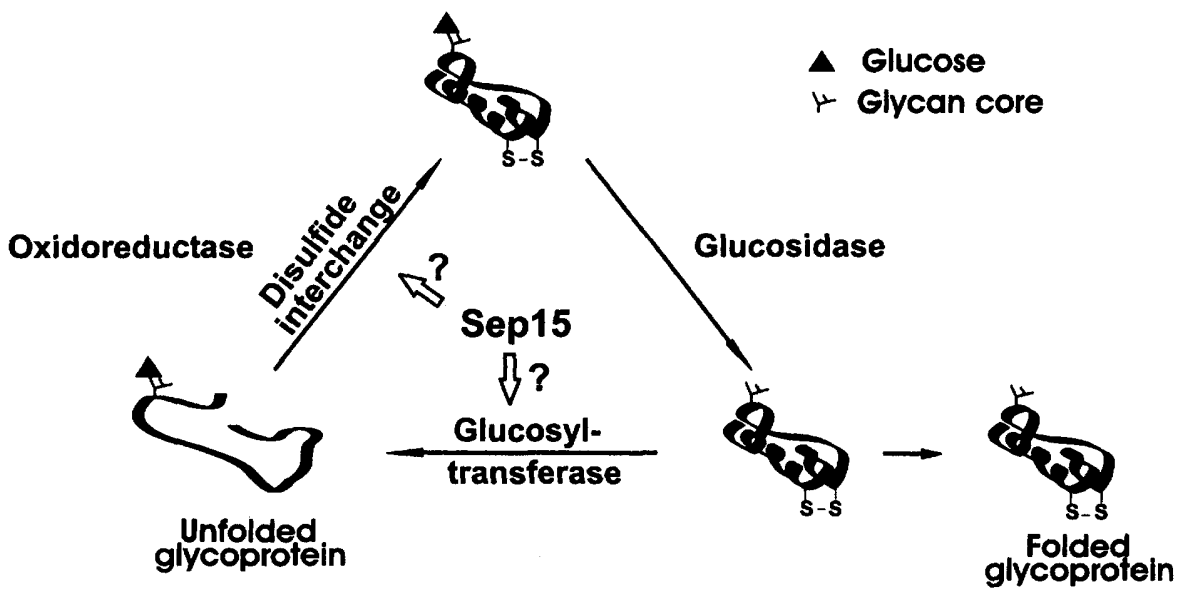

Figure 2. Sep15 and the quality control pathway. UGT recognizes unfolded or improperly folded glycoproteins and catalyzes the transfer of a glucose residue to the glycan. This creates a retention signal and initiates the calnexin/calreticulin cycle. A protein disulfide isomerase binds to calnexin and calreticulin and isomerizes incorrectly formed disulfide bonds. Finally, glucose residue is cleaved by glucosidase, and properly folded glycoproteins are exported form the ER. If not, they are recognized by UGT and the calnexin/calreticulin cycle repeats. The possible functions of Sep 15 in this pathway are shown by open arrows and question marks.

Sequence analysis of the Sep 15 family members identified two distinct domains within this selenoprotein: a C-terminal thioredoxin-like domain that contains the redox active $\mathrm{CxU}$ motif and a novel cysteine-rich domain located in the $\mathrm{N}$-terminal part of the protein (Figure 3). The latter domain exclusively mediates the interaction with UGT and contains six cysteine residues, which are highly conserved among Sep15 proteins. In contrast to Sep15, this domain is absent in its homologue selenoprotein M (SelM), and SelM does not interact with UGT. Mutational studies have shown that substitution of any of the six conserved cysteine residues with serines disrupts the interaction between Sep15 and UGT. As four of these six cysteines form a pair of $\mathrm{CxxC}$ motifs, there was a possibility that these motifs were involved in coordination of metal ions. However, neither cysteine-rich domain itself coordinated metal ions, nor was the formation of Sep15-UGT complex mediated by metals [24] suggesting that these conserved cysteine residues likely form intramolecular disulfide bonds. Site-directed mutagenesis of cysteine residues may disrupt proper arrangement of the 
disulfide bonds and inhibit protein-protein interaction between Sep15 and UGT.

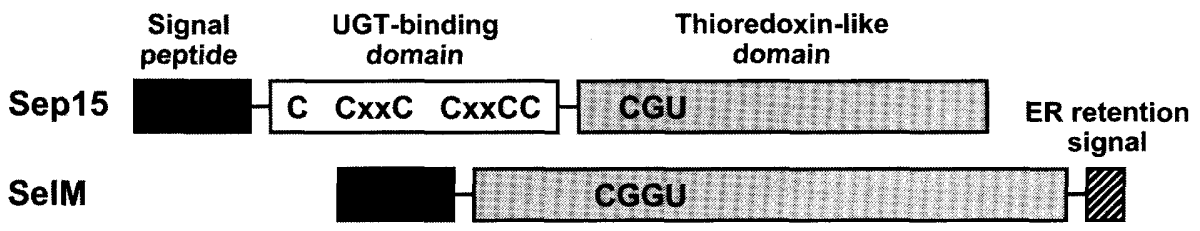

Figure 3. Schematic illustration of the domain arrangement of Sep 15 and SelM. Both selenoproteins encode an N-terminal signal peptide (colored black); one selenocysteine (U) residue; and a thioredoxin-like domain (colored gray). The N-terminal extension of Sep 15 containing six highly conserved cysteine residues has been labeled as the UGT-binding domain.

Consistent with the ER localization of UGT, Sep15 was also localized to the ER, and its N-terminal signal peptide, which was cleaved in the mature protein, was necessary for the ER translocation [6]. In contrast, the Cterminus of Sep15 lacked a typical ER retention signal suggesting that location of Sep15 in this cellular compartment is the result of the interaction with UGT via the $\mathrm{N}$-terminal cysteine-rich domain.

\section{Thiol-disulfide oxidoreductase function}

The solution NMR structures of the thioredoxin-like domain of Sep15 from Drosophila melanogaster and SelM from Mus musculus have been identified [26]. The structural studies revealed that both Sep15 and SelM have a thioredoxin-like fold and suggested a thiol-disulfide oxidoreductase function for these selenoproteins. Although the precise biological function of Sep15 remains unknown, its surface-accessible $\mathrm{CxU}$ motif, located in the $\mathrm{C}$ terminal redox domain, may participate in the reduction, isomerization or oxidation of disulfide bonds and facilitate protein folding (Figure 2). The redox potential of Drosophila Sep15, which naturally encodes a cysteine residue in place of the selenocysteine in the redox-active $\mathrm{CxU}$ motif, was measured to be $-225 \mathrm{mV}$. This redox potential is higher than that of the strong disulfide reductant thioredoxin $(-270 \mathrm{mV}[27,28])$, but is lower than that of the dithiol oxidase DsbA $(-122 \mathrm{mV}[29,30])$. However, the redox potential of Sep15 is within the range of the redox potentials of disulfide reshuffling enzymes, such as PDI (-175 $\mathrm{mV}$ [27]), indicating that Sep15 may function as a disulfide isomerase. Although the measured redox potential is close to that of the protein disulfide isomerase, the possibility cannot be excluded that biological activity of Sep 15 in vivo may be affected by proteinprotein interactions with other ER resident proteins and available 
donors/acceptors of electrons. Furthermore, in contrast to protein disulfide isomerase and its broad substrate specificity, Sep 15 may service a restricted group of protein substrates as demonstrated for protein disulfide isomerase ERp57, which functions exclusively as an isomerase for partially folded glycoproteins that are bound to the chaperones calnexin and calreticulin $[19,22,31]$. In this case, UGT, which recognizes improperly folded glycoproteins, may serve as a primary binding site for Sep 15 protein substrates (analogous to the role of non-catalytic b'-domain of human protein disulfide isomerase).

\section{Expression pattern and regulation of Sep15 expression by dietary selenium}

Expression of the Sep15 gene was examined in several mouse and human tissues by northern blot and immunoblot analyses [5]. The highest levels of gene expression were observed in prostate, liver, kidney, testes and brain, while lower levels were found in lung, spleen and skeletal muscle.

Dietary selenium has been shown to regulate the expression of selenoproteins and the abundance of corresponding mRNAs by acting at both transcriptional and translational levels. For example, selenium deficiency is known to result in up to a $99 \%$ decrease in the activity of glutathione peroxidase 1 (GPx1) and in up to a $90 \%$ decrease in the abundance of GPx1 mRNA in livers of rats and mice. Similar to GPx1, Sep15 expression was also regulated by selenium availability in liver and kidney, although the changes in expression were less pronounced [26,32]. In contrast, Sep15 expression in testes remained almost constant regardless of the selenium availability, consistent with previous observations that the expression patterns of selenoproteins localized to the liver and kidney are highly responsive to the availability of selenium, while the testes efficiently retain this element under selenium-deficient conditions $[33,34]$.

\section{Sep15 selenoprotein family members}

Sep15 is highly conserved from plants to humans [4] suggesting an evolutionary conserved physiological function among Sep15 proteins. Another ER resident eukaryotic selenoprotein, SelM, a distant homolog of Sep15, has recently been identified and characterized [35]. SelM and Sep15 share $31 \%$ sequence identity in their proposed redox-active domains and encode an N-terminal signal peptide (see Figure 3), which is cleaved in the mature protein after translocation into the ER. In contrast to Sep15, the cysteine-rich UGT-binding domain is absent in SelM, and SelM is likely retained in the ER by a C-terminal retention signal (H/R/K-X-DL). This selenoprotein shows a different expression pattern than Sep15, with the highest expression in the brain. Although the function of SelM has not been firmly established, recent studies provide evidence that decreased expression 
of this protein is associated with Alzheimer's disease and SelM may be involved in protection of neurons from oxidative damage [36].

Recently, a new selenoprotein distantly homologous to Sep15 family members has been identified [37]. This selenoprotein was found only in fish and was designated Fep15 (for fish Sep15-like protein). As observed with SelM, Fep15 contains a known ER retention signal (RDEL) at its C-terminus and was also localized to the ER. Fep15 encodes a single selenocysteine residue. In contrast to Sep15, in which Sec is organized into highly conserved $\mathrm{C} x \mathrm{U}$ motif, and SelM, in which $\mathrm{Sec}$ is present within $\mathrm{CxxU}$ motif, Fep15 has valine in place of the conserved cysteine. Moreover, Fep15 does not have any conserved cysteine residues, and in some of the Fep 15 sequences cysteines are not present at all. Thus, this selenoprotein has a distinct catalytic mechanism that may involve formation of selenenic acid or selenenylsulfide bond with a cysteine residue in another protein or low molecular weight thiol, such as glutathione [38]. Another unique feature of this novel selenoprotein is that it is present exclusively in selenocysteinecontaining form, while other members of the Sep 15 protein family exist in the form of both selenocysteine- and cysteine-containing proteins. Furthermore, the very narrow distribution of Fep 15 among fishes suggests that this protein may have a highly specialized function.

\section{Acknowledgments}

This work is supported by NIH grant CA080946 to VNG and the Intramural Research Program of the National Institutes of Health, National Cancer Institute, Center for Cancer Research to DLH.

\section{References}

1. Clark LC, Combs GF, Turnbull BW, Slate EH, Chalker DK, Chow J, Davis LS, Glover RA, Graham GF, Gross EG, Krongrad A, Lesher JL, Park HK, Sanders BB, Smith CL, Taylor JR 1996 JAMA 276:1957

2. Zhang Z, Kimura M, Itokawa Y 1997 Biol Trace Elem Res 57:147

3. Ip C, Dong Y, Ganther HE 2002 Cancer Metastasis Rev 21:281

4. Gladyshev VN, Jeang KT, Wootton JC, Hatfield DL 1998 J Biol Chem 273:8910

5. Kumaraswamy E, Malykh A, Korotkov KV, Kozyavkin S, Hu Y, Kwon SY, Moustafa ME, Carlson BA, Berry MJ, Lee BJ, Hatfield DL, Diamond AM, Gladyshev VN $2000 \mathrm{~J}$ Biol Chem 275:35540

6. Korotkov KV, Kumaraswamy E, Zhou Y, Hatfield DL, Gladyshev VN $2001 \mathrm{~J}$ Biol Chem 276:15330

7. Hu YJ, Korotkov KV, Mehta R, Hatfield DL, Rotimi CN, Luke A, Prewitt TE, Cooper RS, Stock W, Vokes EE, Dolan ME, Gladyshev VN, Diamond AM 2001 Cancer Res 61:2307

8. Nasr MA, Hu YJ, Diamond AM 2003 Cancer Ther 1:307

9. Apostolou S, Klein JO, Mitsuuchi Y, Shetler JN, Poulikakos PI, Jhanwar SC, Kruger WD, Testa JR 2004 Oncogene 23:5032

10. Apostolou S, De Rienzo A, Murthy SS, Jhanwar SC, Testa JR 1999 Cell 97:684

11. Cheung TH, Chung TK, Poon CS, Hampton GM, Wang VW, Wong YF 1999 Cancer 86:1294 
12. Kumaraswamy E, Korotkov KV, Diamond AM, Gladyshev VN, Hatfield DL 2002 Methods Enzymol 347:187

13. Daniels R, Kurowski B, Johnson AE, Hebert DN 2003 Mol Cell 11:79

14. Hebert DN, Foellmer B, Helenius A 1995 Cell $81: 425$

15. Zapun A, Petrescu SM, Rudd PM, Dwek RA, Thomas DY, Bergeron JJ 1997 Cell 88:29

16. Ellgaard L, Riek R, Herrmann T, Guntert P, Braun D, Helenius A, Wuthrich K 2001 Proc Natl Acad Sci U S A 98:3133

17. Schrag JD, Bergeron JJ, Li Y, Borisova S, Hahn M, Thomas DY, Cygler M $2001 \mathrm{Mol}$ Cell 8:633

18. Kapoor M, Srinivas H, Kandiah E, Gemma E, Ellgaard L, Oscarson S, Helenius A, Surolia A 2003 J Biol Chem 278:6194

19. Zapun A, Darby NJ, Tessier DC, Michalak M, Bergeron JJ, Thomas DY $1998 \mathrm{~J}$ Biol Chem 273:6009

20. Molinari M, Helenius A 1999 Nature 402:90

21. Molinari M, Helenius A 2000 Science 288:331

22. Frickel EM, Riek R, Jelesarov I, Helenius A, Wuthrich K, Ellgaard L 2002 Proc Natl Acad Sci U S A 99:1954

23. Leach MR, Cohen-Doyle MF, Thomas DY, Williams DB 2002 J Biol Chem 277:29686

24. Labunskyy VM, Ferguson AD, Fomenko DE, Chelliah Y, Hatfield DL, Gladyshev VN 2005 J Biol Chem 280:37839

25. Shen X, Ellis RE, Sakaki K, Kaufman RJ 2005 PLoS Genet 1:e37

26. Ferguson AD, Labunskyy VM, Fomenko DE, Arac D, Chelliah Y, Amezcua CA, Rizo J, Gladyshev VN, Deisenhofer J $2005 \mathrm{~J}$ Biol Chem (in press)

27. Lundstrom J, Holmgren A 1993 Biochemistry 32:6649

28. Mossner E, Huber-Wunderlich M, Glockshuber R 1998 Protein Sci 7:1233

29. Inaba $\mathrm{K}$, Ito $\mathrm{K} 2002 \mathrm{EMBO} J \mathrm{~J} 21: 2646$

30. Huber-Wunderlich M, Glockshuber R 1998 Fold Des 3:161

31. Pollock S, Kozlov G, Pelletier MF, Trempe JF, Jansen G, Sitnikov D, Bergeron JJ, Gehring K, Ekiel I, Thomas DY 2004 EMBO J 23:1020

32. Novoselov SV, Calvisi DV, Labunskyy VM, Factor VM, Carlson BA, Fomenko DE, Moustafa ME, Hatfield DL, Gladyshev VN 2005 Oncogene (in press)

33. Hill KE, Lyons PR, Burk RF 1992 Biochem Biophys Res Commun 185:260

34. Behne D, Hilmert H, Scheid S, Gessner H, Elger W 1988 Biochim Biophys Acta 966:12

35. Korotkov KV, Novoselov SV, Hatfield DL, Gladyshev VN $2002 \mathrm{Mol}$ Cell Biol 22:1402

36. Hwang DY, Cho JS, Oh JH, Shim SB, Jee SW, Lee SH, Seo SJ, Lee SK, Kim YK 2005 Neurochem Res 30:1009

37. Novoselov SV, Hua D, Lobanov AV, Gladyshev VN 2005 Biochem J (in press)

38. Kim HY, Gladyshev VN 2005 PLoS Biol 3:e375 